\title{
Extracellular matrix metalloproteinase inducer expression in the baboon endometrium: menstrual cycle and endometriosis
}

\author{
A G Braundmeier ${ }^{1,2}$, A T Fazleabas ${ }^{2}$ and R A Nowak ${ }^{1}$ \\ ${ }^{1}$ Department of Animal Sciences, University of Illinois, 1207 West Gregory Drive, Urbana, Illinois 61801, USA and \\ ${ }^{2}$ Department of Obstetrics Gynecology and Reproductive Biology, Michigan State University, 333 Bostwick Avenue \\ NE, Grand Rapids, Michigan 49503, USA
}

Correspondence should be addressed to R A Nowak; Email: ranowak@uiuc.edu

\begin{abstract}
Extracellular matrix metalloproteinase inducer (EMMPRIN; BSG) regulates tissue remodeling through matrix metalloproteinases (MMPs). In human and non-human primates, endometrial remodeling is important for menstruation and the pathogenesis of endometriosis. We hypothesized that as in humans, BSG and MMPs are expressed in the endometrium of cycling baboons, and their expression is hormonally regulated by ovarian hormones, but endometriosis disrupts this regulation. BSG expression was evaluated in the baboon endometrium by q-PCR and immunohistochemistry. In the endometrium of control cycling animals, BSG mRNA levels were highest in late secretory stage tissue. BSG protein localized to glandular epithelial cells during the proliferative phase; whereas, secretory stage tissues expressed BSG in glandular and luminal epithelia with weak stromal staining. Several MMPs were differentially expressed throughout the menstrual cycle with the highest levels found during menstruation. In ovariectomized animals, BSG endometrial mRNA levels were highest with treatment of both estrogen and progesterone than that with only estrogen. Estrogen alone resulted in BSG protein localization primarily in the endometrial glandular epithelia, while estrogen and progesterone treatment displayed BSG protein localization in both the glandular and stromal cells. Exogenous hormone treatment resulted in differential expression patterns of all MMPs compared with the control cycling animals. In the eutopic endometrium of endometriotic animals, BSG mRNA levels and protein were elevated early but decreased later in disease progression. Endometriosis elevated the expression of all MMPs except MMP7 compared with the control animals. In baboons, BSG and MMPendometrial expression is regulated by both ovarian hormones, and their expression patterns are dysregulated in endometriotic animals.

Reproduction (2010) 140 911-920
\end{abstract}

\section{Introduction}

Extracellular matrix metalloproteinase inducer (EMMPRIN; $B S G)$ is a member of the immunoglobulin superfamily, which includes $\mathrm{T}$ cell receptors, neural cell adhesion molecules, and major histocompatibility complex antigens. This glycoprotein was first identified as tumor cell collagenase stimulatory factor (TCSF), a tumor cell surface molecule that stimulates nearby fibroblasts to produce matrix metalloproteinases (MMPs). Since its discovery in tumor cells, BSG has also been shown to play a role in several normal physiological functions such as inflammation and reproduction (Igakura et al. 1998, Muramatsu \& Miyauchi 2003). The ability of BSG to stimulate MMP production is highly dependent on its state of glycosylation, as deglycosylation reduces MMP stimulation (Sun \& Hemler 2001).

We, along with others, have previously shown that $B S G$ was expressed in human endometrium and might regulate the expression of MMPs throughout the menstrual cycle to control the breakdown and regeneration of the endometrium (Noguchi et al. 2003, Braundmeier et al. 2006). Numerous reports have shown the importance of MMPs for normal ovarian and uterine function and their involvement in reproductive diseases (reviewed in Curry \& Osteen (2003)).

Recently, we have evaluated BSG expression in the eutopic and ectopic endometria of women with the gynecological disease endometriosis (Braundmeier et al. 2006). Endometriosis is a benign gynecological disease in which uterine endometrial fragments grow in areas of the body other than the uterus such as the peritoneal cavity. It is generally accepted that these endometrial fragments, consisting of uterine luminal and glandular epithelial cells and underlying endometrial stromal cells, exfoliate during menstruation, flow out by retrograde menstruation into the peritoneal cavity via the oviducts, and implant into the peritoneal mesothelium (Sampson 1940).

Several investigators have reported the dysregulation of MMPs in the eutopic and ectopic endometria in 
both women and animal models of endometriosis (Bruner-Tran et al. 2002, Osteen et al. 2002, Gaetje et al. 2007, Monckedieck et al. 2009). We believe that the expression of BSG by the ectopic endometrial lesions may be involved in the invasion of ectopic endometrium into the peritoneal mesothelium due to stimulation of MMP production by uterine stromal fibroblasts (Braundmeier et al. 2006). We found that BSG expression was elevated in the eutopic endometrium of women with endometriosis, and this could explain why although the majority of women experience retrograde menstruation only some women develop clinical endometriosis. These data indicate that the eutopic expression of BSG may be important for normal fertility, but the overexpression of BSG by the eutopic and ectopic endometria may be advantageous for the establishment of endometriosis.

The baboon (Papio anubis) is an excellent model for the study of biological and pathological gynecological conditions. Unlike rodents and mice, baboons have a menstrual cycle similar to humans both in duration and in endometrial remodeling. In addition, baboons also develop spontaneous endometriosis with ectopic lesions resembling those of women (Merrill 1968, Folse \& Stout 1978), but disease can also be induced by the injection of menstrual effluent into the pelvic cavity (D'Hooghe 1997, Fazleabas et al. 2002) allowing investigators to study disease progression from the initial onset of the disease.

To date, there has been little evidence on the expression profile of MMPs and their regulators of nonhuman primates for reproductive function (Brenner et al. 1996, Cox et al. 2000). For these reasons, we have used the baboon as a model to study changes in the expression of BSG and several MMPs throughout the menstrual cycle in disease-free animals and also in an induced model of endometriosis. In addition, we have used this model to test the ovarian hormonal regulation of $B S G$ gene expression and protein localization as well as of $M M P$ expression. We hypothesized that as in humans, endometrial BSG and MMP expression will be regulated by ovarian hormones, and this regulation will be altered in diseased animals.

\section{Results}

\section{BSG gene expression in cycling eutopic endometrium}

To examine the changes in BSG gene expression throughout the menstrual cycle in normal disease-free animals, endometrial biopsies were collected during the proliferative and secretory stages of the cycle and were compared to menstrual tissue $(n=4)$. RNA samples were analyzed by real-time PCR to quantify differences in the mRNA levels at each cycle stage. We found that BSG mRNA levels were similar between the menstrual and proliferative stage tissues (Fig. 1; top panel). We also found that as the cycle progressed into the secretory phase, BSG mRNA levels were highest during the late secretory phase than during the late proliferative phase of the cycle (Fig. 1; top panel).

\section{BSG protein localization in cycling eutopic endometrium}

To determine the pattern of BSG protein localization during different stages of the menstrual cycle in the control animals, endometrial tissues were fixed and
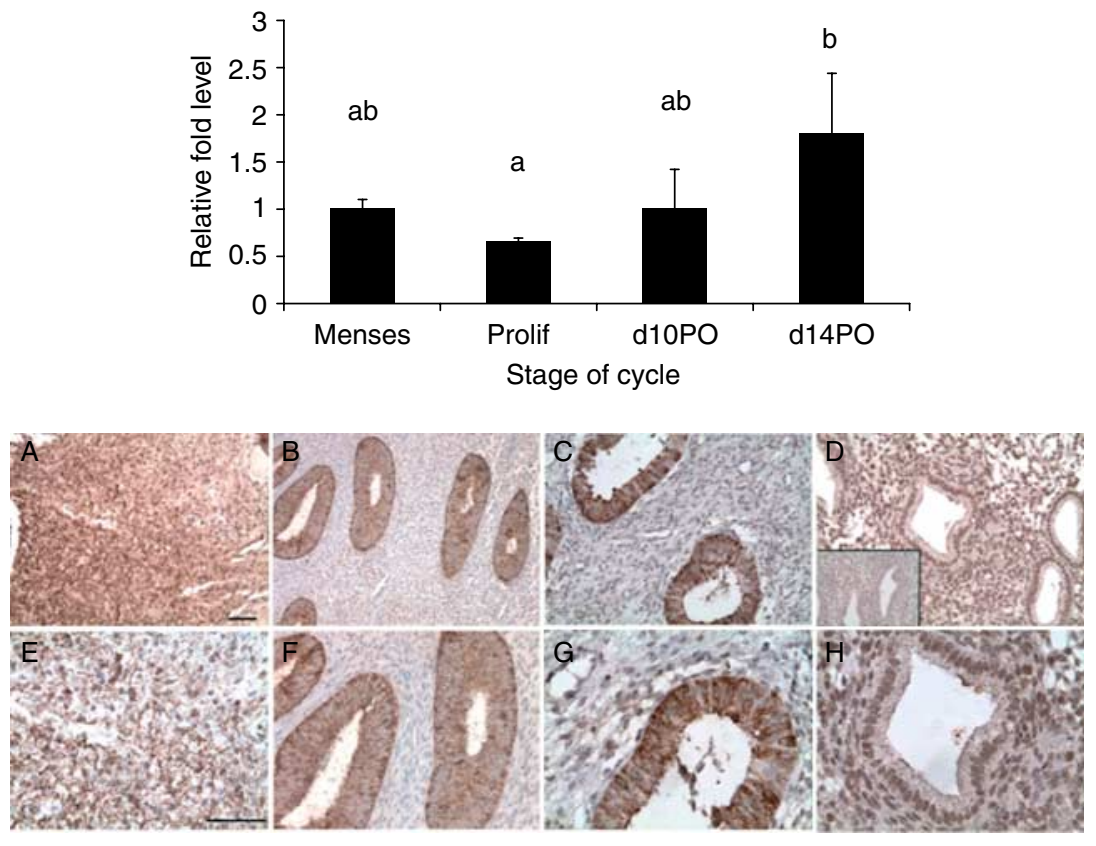

Figure 1 Top panel: quantitative PCR of BSG mRNA levels in the eutopic endometrium of normal cycling baboons. Relative fold levels of BSG mRNA at each stage of the cycle were normalized to BSG mRNA levels at the time of menses. H3F3 mRNA levels served as an endogenous control (statistical significance from controls is indicated by different letters $P<0.05)$. d10PO $=$ day 10 post ovulation and $\mathrm{d} 14 \mathrm{PO}=$ day 14 post ovulation. Bottom panel: immunohistochemical analysis of BSG protein localization in the eutopic endometrium of normal cycling baboons. (A and $\mathrm{E}$ ) Menses, (B and $\mathrm{F}$ ) proliferative, (C and G) d10 PO (day 10 post ovulation), (D and $\mathrm{H}) \mathrm{d} 14 \mathrm{PO}$ (day 14 post ovulation). $\mathrm{D}$ inset $=$ isotype control lgG. A-D bar $=100 \mu \mathrm{m}$, $\mathrm{E}-\mathrm{H}$ bar $=50 \mu \mathrm{m}$ ( $n=3$ for all the stages). 
analyzed by immunohistochemistry. Endometrial tissues were collected from three animals during the late proliferative, mid-secretory, and late secretory stages of the cycle and were compared to tissue fragments in the menstrual effluent. We found that BSG protein was present in the endometrium during all the stages of the menstrual cycle (Fig. 1; bottom panel). BSG protein was expressed in the menstrual tissue, but determining cellular localization was difficult because of the fragmentation of the tissues in the menstrual effluent (Fig. 1A and E; bottom panel). BSG protein was localized primarily to the glandular epithelial cells of the endometrium during the late proliferative stage (Fig. 1B and $\mathrm{F}$; bottom panel). In the early and late secretory phases of the cycle, BSG expression did not change in the glandular epithelial cells (Fig. 1C, D, G, and H; bottom panel). BSG protein expression in the underlying stromal tissue was weak throughout both the proliferative and the mid-secretory stage tissues but was greater in the late secretory stage tissues (Fig. 1D and $\mathrm{H}$; bottom panel). The glandular epithelium of menstrual tissue had relatively weak BSG expression compared with the robust expression in the stroma (Fig. 1A and E; bottom panel).

\section{MMP expression in cycling baboon endometrium}

The expression pattern of several MMPs (MMP1, -2, -3, and -7) was compared with BSG expression in the control cycling animals. MMP1 and -3 levels were highly expressed during menstruation but then decreased during the proliferative and secretory stages of the menstrual cycle (Fig. 2A and C; and top panel). The expression of MMP2 was elevated during menstruation but was decreased in the proliferative and mid-secretory stage endometrium (Fig. 2B; and top panel). In contrast, MMP7 expression was elevated during menstruation and the proliferative stage but decreased during the secretory stage (Fig. 2D; and top panel). The expression of each gene was normalized to the background signal and calibrated against H3.3 (H3F3) as a loading control.

\section{BSG gene expression in eutopic endometrium of ovariectomized animals}

To investigate the potential regulation of BSG expression by ovarian steroid hormones, we utilized an ovariectomized baboon model where exogenous hormones were administered s.c. to replicate the late proliferative $(n=4)$, mid-secretory $(n=4)$, and late secretory $(n=4)$ phases of the menstrual cycle. Oophorectomy caused complete regression of the endometrial lining in animals given sham implants, therefore we could not obtain control endometrial tissue from ovariectomized animals for the gene expression analysis. As a consequence, we compared the endometrium from exogenous
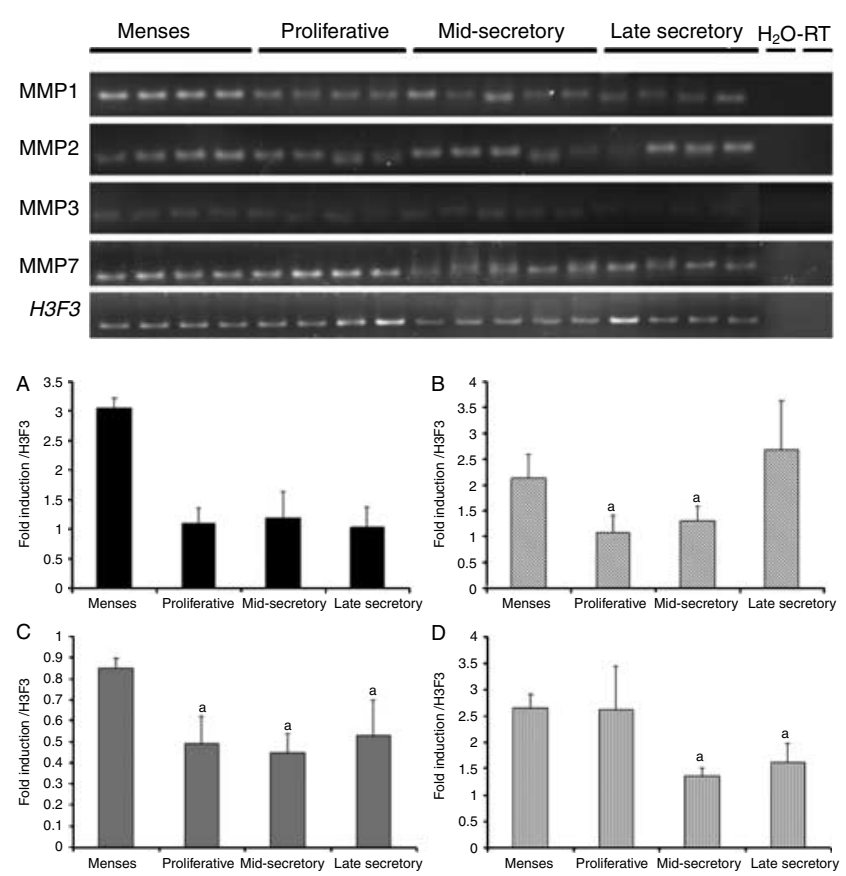

Figure 2 Top panel: semi-quantitative PCR of $M M P$ gene expression in the cycling endometrium. Bottom panel: densitometric analysis of MMP1, -2, -3 , and -7 for each cycle stage was normalized to background and calibrated to $\mathrm{H} 3 \mathrm{~F} 3$ endogenous control gene expression; $A=M M P 1$, $B=M M P 2, C=M M P 3$, and D=MMP7 (statistical difference from controls is indicated by different letters, $P<0.05)$.

hormone-treated baboons to that obtained at menstruation. Chronic estrogen alone did not stimulate $B S G$ gene expression above that of normal menstrual endometrium. However, the endometrium obtained from animals that were estrogen primed and then treated with either estrogen + progesterone for 7 days or progesterone alone for 14 days showed enhanced $B S G$ gene expression $(P<0.05$; Fig. 3 top panel). We did not detect a significant difference between estrogen+progesterone treatment for 7 days or progesterone for 14 days. These data indicate that in the baboon endometrium, estrogen alone does not stimulate $B S G$ expression, but rather estrogen works in combination with progesterone to drive BSG expression.

\section{BSG protein localization in eutopic endometrium of ovariectomized animals}

After determining that estrogen and progesterone drove $B S G$ gene expression, we analyzed BSG protein localization in the same endometrial tissues. In the presence of estrogen alone, BSG protein localized primarily to the glandular epithelial cells in the endometrium (Fig. 3A and D; bottom panel). However, in the presence of estrogen and progesterone after 7 days of treatment (mid-secretory phase), BSG protein localization was enhanced in the glandular epithelial cells in comparison with the presence of estrogen alone (Fig. 3A and $B$; bottom panel). In animals treated with estrogen 

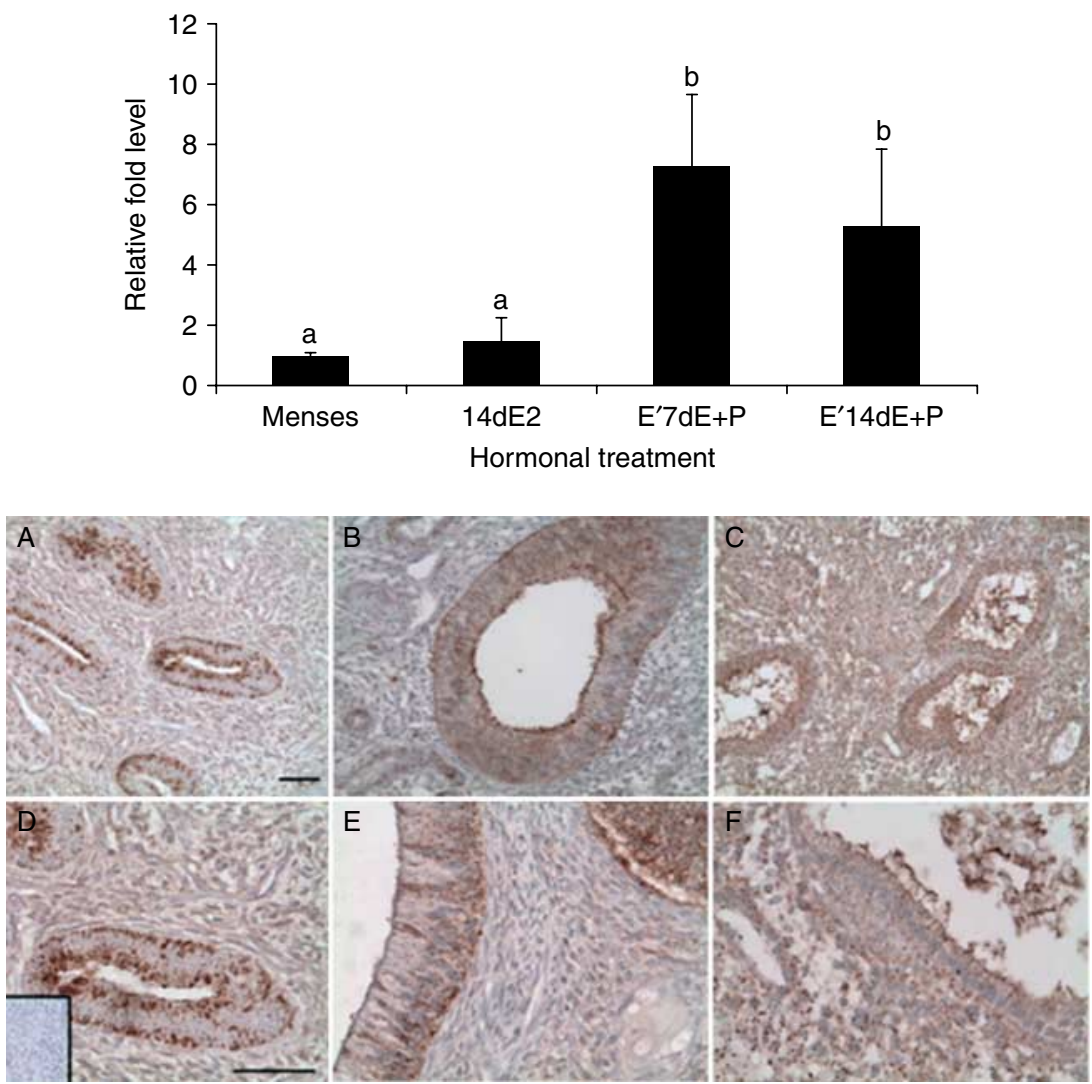

Figure 3 Top panel: quantitative PCR of BSG mRNA levels in the eutopic endometrium of ovariectomized baboons. Relative fold levels of BSG mRNA for each treatment were normalized to $B S G$ mRNA levels at the time of menses. H3F3 mRNA levels served as an endogenous control (statistical significance from controls is indicated by different letters $P<0.05) .14 \mathrm{dE} 2=14$ days of estrogen treatment, $E^{\prime} 7 \mathrm{dE}+\mathrm{P}=$ estrogen priming for 14 days followed by 7 days of estrogen and progesterone, $\mathrm{E}^{\prime} 14 \mathrm{dE}+\mathrm{P}=$ estrogen priming for 14 days followed by 14 days of estrogen and progesterone. Bottom panel: immunohistochemical analysis of BSG protein localization in the eutopic endometrium of ovariectomized hormone-treated baboons. A and $\mathrm{D}=14$ days of estrogen treatment (proliferative), $\mathrm{B}$ and $\mathrm{E}=$ estrogen priming for 14 days followed by 7 days of estrogen and progesterone, and $\mathrm{C}$ and $\mathrm{F}=$ estrogen priming for 14 days followed by 14 days of estrogen and progesterone. Inset in $\mathrm{D}$ is isotype control $\operatorname{lgG}$. Scale bar equals $50 \mu \mathrm{m}$. A-C images are at the same magnification, and $\mathrm{D}-\mathrm{F}$ images are at the same magnification ( $n=4$ for all the treatments). and progesterone for 14 days (late secretory phase), BSG protein localized to both the glandular epithelial cells and endometrial stromal cells (Fig. 3C and F; bottom panel). This increased localization of BSG protein to both the epithelial and stromal cell types reflects the increased gene expression levels found in the late secretory phase of normal cycling and ovariectomized animals.

\section{MMP expression in ovariectomized animals}

To examine ovarian hormonal regulation of MMPs in the baboon endometrium, we again utilized ovariectomized animals given exogenous hormone replacement. Hormonal supplementation changed the expression profile of each MMP and was different from those observed in the cycling animals. Chronic estrogen alone resulted in reduction of MMP3 and -7 but enhanced MMP2 levels while having no effect on MMP1 (Fig. 4; top and bottom panels). Estrogen priming followed by the combined treatment of estrogen and progesterone resulted in decreased MMP1, -3, and -7 levels while increasing MMP2 levels (Fig. 4; top and bottom panels). Estrogen priming followed by progesterone alone elevated MMP1 and -2 expression, decreased MMP3 expression but had no effect on MMP7 expression (Fig. 4; top and bottom panels).

\section{BSG gene expression in eutopic endometrium during disease progression}

To examine the effects of the presence of ectopic endometriotic lesions on BSG gene expression in the eutopic endometrium, eutopic endometrial biopsies were collected on day 10 post ovulation $(\mathrm{PO})$ at 1 $(n=4), 3(n=4)$, and 8-10 months of disease $(n=5)$. In the eutopic endometrium, BSG mRNA levels were quantified by real-time PCR and normalized to day 10 PO disease-free controls $(n=3)$. BSG mRNA levels in the eutopic endometrium increased significantly at 1 and 3 months of disease but then decreased by $8-10$ months of disease to levels observed in the control animals (Fig. 5; top panel). Owing to the small number of lesions harvested at the time of surgery, we were not able to analyze the mRNA levels from the ectopic endometrium. We then evaluated whether the increase in BSG mRNA during the early stages of disease development corresponded with an increase in BSG protein expression during these same timepoints in the disease.

\section{BSG protein expression in eutopic and ectopic endometria of diseased animals}

BSG protein expression was compared in matched eutopic and ectopic tissues collected at different 


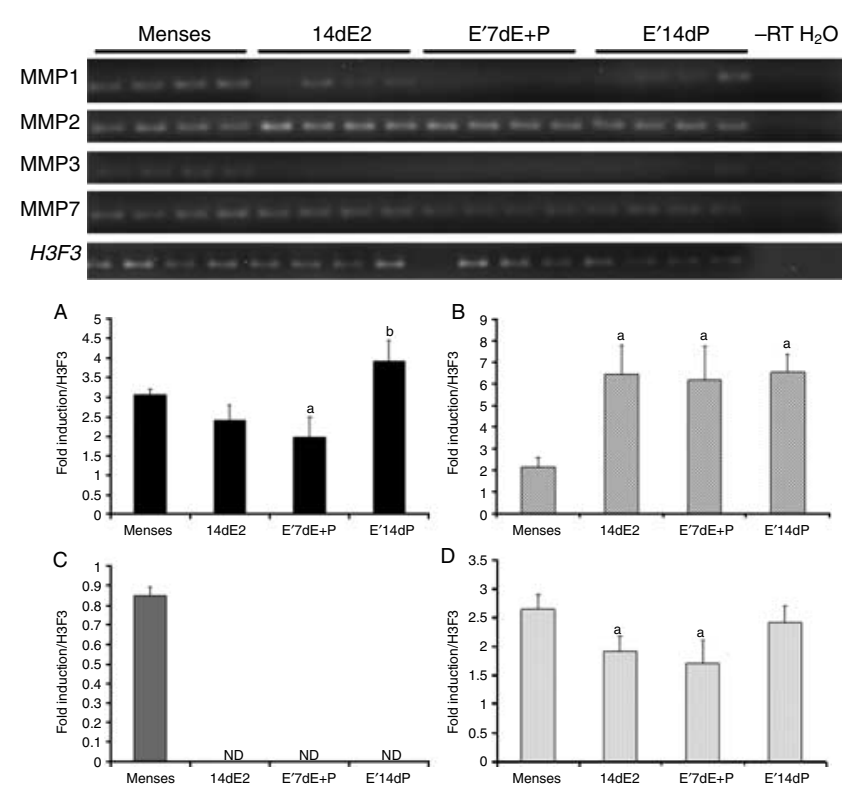

Figure 4 Top panel: semi-quantitative PCR of $M M P$ gene expression in the endometrium from ovariectomized animals. Bottom panel:

densitometric analysis of MMP1, -2, -3, and -7 for each cycle stage was normalized to background and calibrated to $\mathrm{H} 3 \mathrm{~F} 3$ endogenous control gene expression; $A=M M P 1, B=M M P 2, C=M M P 3$, and $D=M M P 7$.

timepoints during the disease progression from animals with induced endometriosis. The eutopic and ectopic endometria were collected at 1, 3, 6, and 15 months after establishment of endometriosis at day $10 \mathrm{PO}$ for the same three animals at each timepoint. Tissues were analyzed by immunohistochemistry to examine the expression and localization of BSG protein.

We found that the eutopic endometrium from diseased animals showed increased stromal BSG protein expression compared with day 10 PO disease-free controls at all timepoints of the disease (Fig. 5A-E compared with Fig. 5N; bottom panel). Eutopic BSG protein expression was increased at 6 and 9 months of disease compared with that at 3 months but then decreased at 15 months (Fig. 5A-D and F-I; bottom panel). In spontaneous disease, BSG expression was elevated above that of the control animals (Fig. 5E and J compared to $\mathrm{N}$; bottom panel). BSG protein expression in the ectopic endometrium closely resembled that of matched eutopic endometrial samples, in that both the glandular and stromal cells showed increased BSG immunoreactivity at 6 months and decreased expression at 15 months (Fig. 5K-M; bottom panel). This expression pattern was evident in all the three animals analyzed.

\section{MMP expression in eutopic endometrium during disease progression}

To determine if the presence of ectopic endometrial lesions and the duration of disease altered the expression of MMPs, we evaluated their expression in the eutopic endometrium of diseased animals during different stages of disease progression. The presence of ectopic lesions enhanced the expression of MMP1,-2, -3 but not of MMP7 (Fig. 6; top and bottom panels). At the early stages of disease, MMP3 levels were elevated above that of control mid-secretory stage endometrium and continued to rise through disease progression (Fig. 6; top and bottom panels). At 6 months post induction of disease, MMP1 levels were elevated and remained high until 12 months post induction (Fig. 6; top and bottom panels). In contrast, MMP2 levels were elevated at 6 months post induction but then declined at 12 months post induction (Fig. 6; top and bottom panels). We analyzed four animals from each treatment group, and all the animals were compared to the control mid-secretory stage endometrium.

\section{Discussion}

The primate endometrium undergoes extensive remodeling throughout the menstrual cycle, which requires the activation of several extracellular matrix proteins and MMPs. The expression profiles of several MMPs (reviewed in Curry \& Osteen (2003)) and BSG (a potent MMP inducer (Braundmeier et al. 2006)) have been reported throughout the human menstrual cycle. In addition, it has been shown that progesterone along with cytokines has an inhibitory effect on BSG and MMP expression (Salamonsen et al. 1997, Bruner et al. 1999, Salamonsen \& Woolley 1999, Braundmeier \& Nowak 2006, Braundmeier et al. 2006). Given the previous data, we wanted to examine whether BSG expression was similar in the non-human primate endometrium during the menstrual cycle, if BSG expression was regulated by ovarian hormones and whether BSG and MMP expression were altered with the establishment and progression of endometriosis.

Our results showed that the pattern of BSG expression in the baboon endometrium differed somewhat from what we have reported previously in normal human cycling endometrium (Braundmeier et al. 2006). In cycling human endometrium, BSG mRNA levels were highest in the proliferative stage endometrium and lower in the late secretory stage endometrium. Examination of $B S G$ mRNA levels in the baboon showed that BSG gene expression increased as the cycle progressed with the highest levels reported at d14PO (late secretory phase). Similar to the human endometrium, BSG protein localized primarily to the glandular and luminal epithelial cells in the baboon proliferative and secretory stage tissues. However, unlike the human endometrium, the baboon endometrium displayed relatively weak BSG localization in the stromal cells. In addition, baboon menstrual tissue, like human menstrual tissue, showed little if any BSG immunoreactivity in the glandular epithelial cells, suggesting that there is a loss of BSG expression in these cells at menstruation. In contrast to 

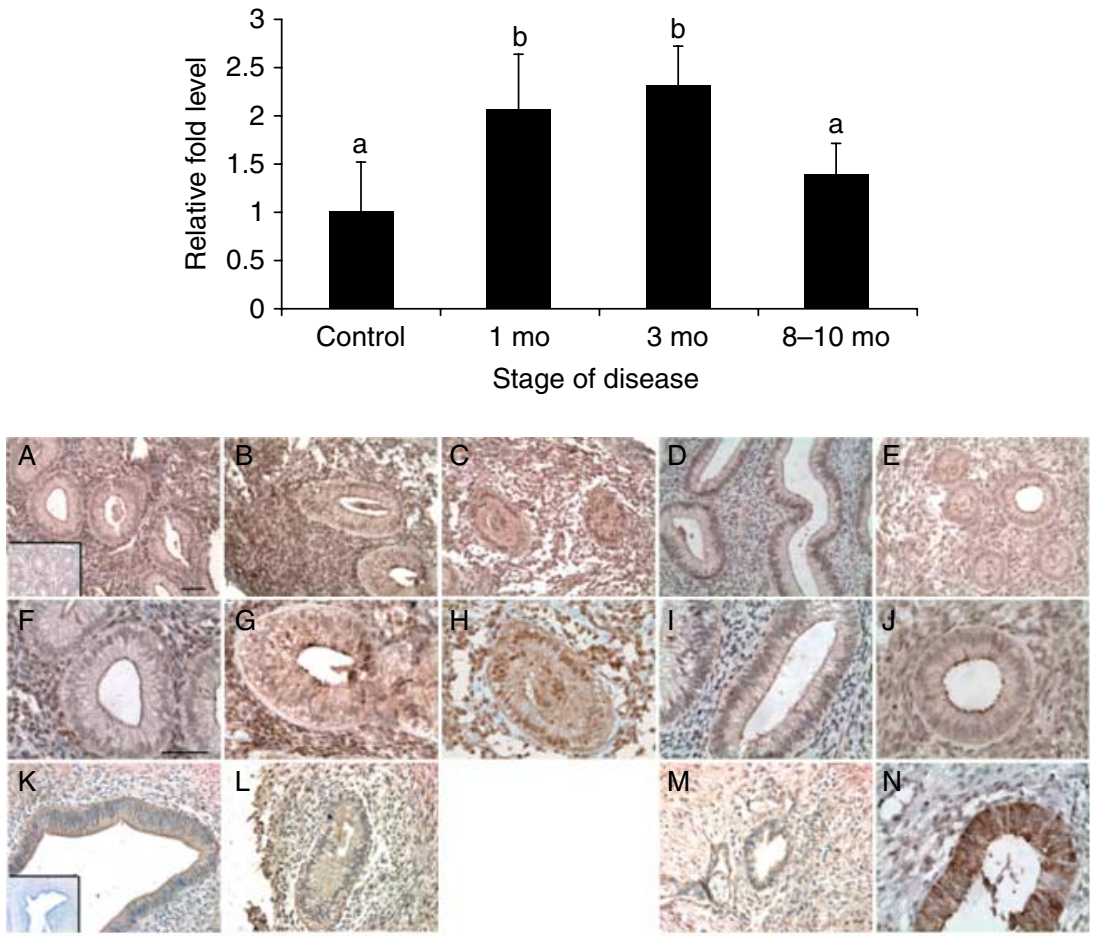

BSG expression, MMP expression levels were highest at menstruation and, other than MMP2, decreased during the secretory stage of the menstrual cycle, which is in agreement with the data published in the human cycling endometrium (Rodgers et al. 1994, Kokorine et al. 1997).

The increase in BSG gene and protein expression throughout the baboon menstrual cycle indicates that BSG may not be regulated by estrogen and progesterone in the same manner as in the human endometrium, but hormonal regulation of endometrial MMP expression is conserved among species. Proliferative human endometrium had the highest levels of BSG expression suggesting that BSG is positively regulated by estrogen and inhibited by high levels of progesterone in the secretory stage endometrium. However, in the baboon endometrium, it appeared that progesterone and estrogen worked together to stimulate BSG expression levels in the secretory stage endometrium. Meanwhile, MMP expression was suppressed during the secretory stage of the menstrual cycle compared with the menstrual tissue, indicating that BSG may not directly regulate MMP expression as it does in the human endometrium. In agreement with the data for the human uterus, we found that BSG expression in both the epithelial and stromal cells increased during the mid-secretory phase of the menstrual cycle and also in response to exogenous estrogen and progesterone treatment for 7 days. We were unable to effectively recapitulate the expression profile of MMPs with our ovariectomized animal model. This may be due to the chronic levels of exogenous hormones in peripheral blood instead of the gradual increase of hormones in intact cycling animals.
The expression of BSG during the mid-secretory phase of the baboon menstrual cycle supports previous data that BSG is important for proper embryonic implantation and endometrial stromal cell decidualization (Chen et al. 2007). Characterization of BSG mRNA and protein during murine implantation and pregnancy indicates that BSG may be important for decidualization of the endometrial stromal cells (Igakura et al. 1998, Xiao et al. 2002). This was supported by the observation that $B S G$ knockout embryos have decreased implantation rates, although they develop normally during preimplantation stages (days 0-4; Igakura et al. 1998).

Although several endometrial proteins are conserved among humans and non-human primates (Giudice 2004, Talbi et al. 2006), the differential hormonal regulation of endometrial proteins in the non-human primate compared with that in the human is consistent for several proteins. For example, $\alpha_{v} \beta_{3}$ and glycodelin that are normally expressed during the receptive window in women are only evident in the baboon endometrium in response to hCG stimulation and in early pregnancy (Fazleabas et al. 1997a, 1997b, 1999, Hausermann et al. 1998). This difference may be due to the progesterone threshold levels in the endometrium of the non-human primate compared with that of the human.

The expression of BSG and MMPs during the primate menstrual cycle and their previously reported importance for successful implantation lead us to investigate $B S G$ and $M M P$ expression in the endometrium of animals with experimentally induced endometriosis. In diseased animals, BSG protein was not only localized to the glandular epithelial cells but was much more evident 

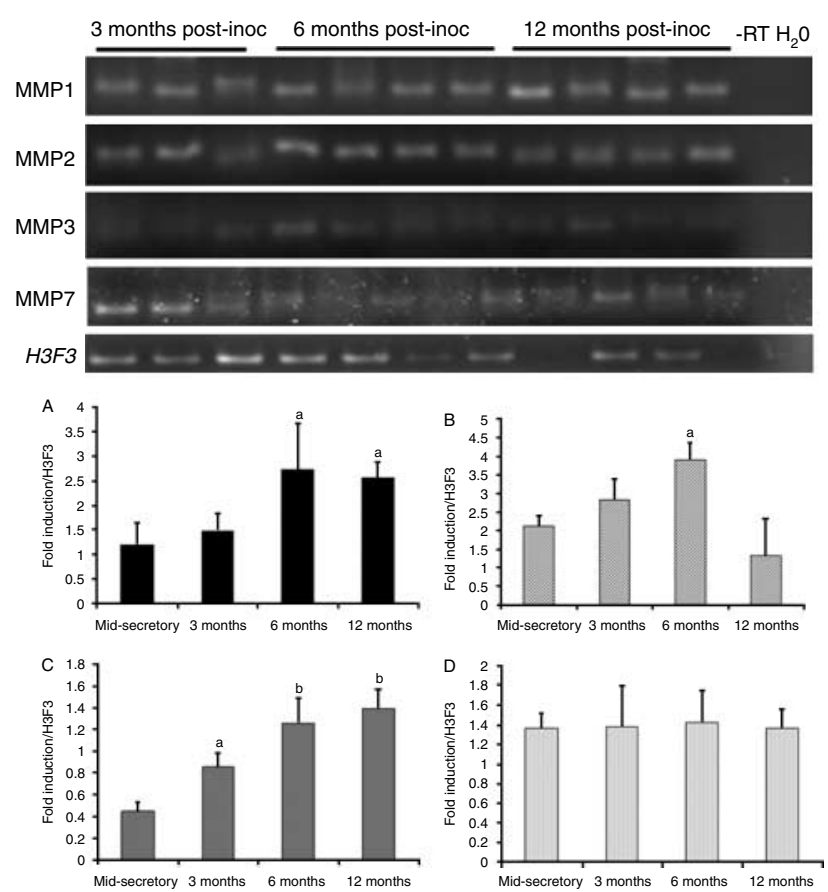

Figure 6 Top panel: semi-quantitative PCR of MMP gene expression in the endometrium from diseased animals. Bottom panel: densitometric analysis of MMP1, $-2,-3$, and -7 for each cycle stage was normalized to background and calibrated to $\mathrm{H} 3 \mathrm{~F} 3$ endogenous control gene expression; $A=M M P 1, B=M M P 2, C=M M P 3$, and $D=M M P 7$ (significance is indicated by different letters, $P<0.05$ ).

in the stromal cells than that in non-diseased animals. This altered BSG expression suggests that the presence of ectopic lesions can alter the behavior of the eutopic endometrium, in agreement with studies that reported that the stromal fibroblasts from baboons with endometriosis are more responsive to a decidualization stimulus (Kim et al. 2007).

Furthermore, it was interesting to observe that the $B S G$ gene and protein expression in the eutopic endometrium increased as the disease progressed but then declined at 8-10 months post induction. In contrast, MMP expression was elevated at the early onset of disease and remained elevated throughout the disease progression. Microarray expression analyses have found that estrogen-regulated genes (including Cry61 and c-fos) that are usually downregulated in the eutopic endometrium during the secretory phase are upregulated until 6 months of the disease progression following which they decrease to control levels. In contrast, progesteroneregulated genes implicated in the eutopic endometrial development are downregulated after the 6-month timepoint (Hastings et al. 2006, Jackson et al. 2007, Kim et al. 2007). The high expression of MMPs late in the disease process supports the development of progesterone resistance that has been reported in women and baboons (Tranguch et al. 2007, Hirota et al. 2008, Aghajanova et al. 2009, Attar et al. 2009, Jones et al. 2009, Fazleabas 2010).
Ectopic endometrial BSG expression closely resembled that of the eutopic endometrium. Ectopic BSG expression may be critical for the establishment and progression of endometriosis. The stimulation of MMPs in the endometriotic stromal cells by BSG may aid in remodeling the mesothelium and in the establishment of angiogenesis at the site of lesion attachment, both events are critical for lesion development. These studies have shown that while endometrial expression of BSG was different in humans compared with that in baboons during the menstrual cycle, BSG expression in the endometrium of endometriotic animals was similar to that reported in human patients (Braundmeier et al. 2006). This suggests that although the hormonal regulation of BSG may be different between the human and the baboon, the expression of MMPs was not altered from that reported in women. The conserved endometrial expression of $B S G$ validates the use of the baboon as a powerful model to investigate gynecological conditions in humans, and understanding the regulation of $B S G$ may lead to therapeutic targets for treating endometriosis.

\section{Materials and Methods}

\section{Animal procedures and induction of endometriosis}

Endometriosis was experimentally induced in olive baboons (P. anubis) by i.p. inoculation of menstrual endometrium on day 2 of two consecutive menstrual cycles, where day 1 was the first day of menses. Details of the inoculation procedure and tissue collection have been described previously in D'Hooghe et al. (1995) and Fazleabas et al. (2002, 2003). Animals were of reproductive age and ranged in weight from 15 to $20 \mathrm{~kg}$. Animals were housed in the animal care facility at the University of Illinois at Chicago, and all studies were approved by the University of Illinois Institutional Animal Care and Use Committee.

\section{Removal of ectopic and eutopic endometria}

Blood samples were collected daily from day 7 through 16 post menstruation (day 1 was the first day of menses) of menstrual cycles during which surgery was to be performed. Serum estradiol $\left(E_{2}\right)$ levels were measured by RIA (DSLabs, Webster, TX, USA). The serum $E_{2}$ peak was taken as day -1 of ovulation, and the day of ovulation was designated as day +1 . All laparoscopies and laparotomies were performed, and tissues were harvested between days 8 and 11 PO, which corresponds to the time of embryo implantation in the baboon. The eutopic and ectopic endometria were collected at 1, 3, 6, and 8-10 months of disease progression following the second inoculation to induce endometriosis. The control endometrial tissues were similarly harvested from animals without disease during menses and the proliferative and secretory phases of the cycle. The eutopic endometria were either snap frozen in liquid nitrogen $\left(\mathrm{LN}_{2}\right)$ for western blot analysis or fixed in $10 \%$ buffered formalin for $24 \mathrm{~h}$ at room temperature for 
immunohistochemical and morphological analysis. As the ectopic endometriotic lesions were small in size, samples were only collected for immunohistochemistry.

\section{Ovariectomized animal model}

Treatment of ovariectomized females was reported in detail in Fazleabas et al. (1988). Briefly, fifteen mature cycling baboons ( $P$. anubis) were ovariectomized by mid-ventral laparotomy. Two months following the ovariectomy, the animals were divided into four groups. The groups were designated as the following: ovariectomized control $(n=3)$, estrogen only for 14 days (estrogen primed) $(n=4)$, estrogen primed then 7 days of estrogen + progesterone $(n=4)$, and estrogen primed then 14 days of progesterone $(n=4)$. Ovarian hormones were administered by the placement of $6 \mathrm{~cm}$ Silastic capsules (cat \#601-335; Dow-Corning, Midland, MI, USA) s.c., and RIA indicated physiological steady-state levels of exogenous hormones in peripheral blood during the treatment period (Fazleabas et al. 1988). Animals treated with estrogen only received one $E_{2}$ implant for 7 days and then an additional $E_{2}$ implant for 7 days, replicating the late proliferative phase of the menstrual cycle. Animals treated with estrogen and progesterone were estrogen primed for 14 days, and then the $E_{2}$ implants were replaced with one $E_{2}$ implant + three $P$ implants for either 7 or 14 days, replicating the mid-secretory and late secretory phases of the menstrual cycle. Endometrial tissue was collected by hysterectomy from ovariectomized baboons with no hormonal treatment, after estrogen priming-late proliferative (day 14), 7 days of estrogen + progesterone-mid-secretory (day 21), and 14 days of estrogen + progesterone-late secretory (day 28) stages.

\section{Immunohistochemistry}

Baboon uterine tissues were fixed in 10\% neutral buffered formalin for $24 \mathrm{~h}$. Tissues were then processed and embedded into paraffin blocks. Tissue blocks were sectioned at $5 \mu \mathrm{m}$ and mounted on poly-L-lysine-coated slides. Antigen retrieval was performed by boiling sections in $10 \mathrm{mM}$ citrate buffer ( $\mathrm{pH}$ 6.0) for $10 \mathrm{~min}$, and endogenous peroxidase activity was quenched with methanol containing $0.3 \%$ hydrogen peroxide for $15 \mathrm{~min}$. Non-specific binding was blocked with $5 \%$ normal rabbit serum in PBS containing 1\% BSA for 20 min. Slides were then incubated with a 1:25 dilution of goat polyclonal antibody against the intracellular domain of recombinant human BSG (Cat\# sc-9754; Santa Cruz Biotechnology, Santa Cruz, CA, USA) in $1 \% \mathrm{BSA}$ in PBS at $4{ }^{\circ} \mathrm{C}$ overnight. Non-specific goat IgG $(2 \mu \mathrm{g} / \mathrm{ml})$ in $1 \%$ BSA in PBS was used as a negative control. Slides were washed three times for 5 min each in PBS then incubated with biotinylated rabbit anti-goat IgG (Vector Labs, Burlingame, CA, USA) diluted 1:100 with 1\% BSA in PBS for
$60 \mathrm{~min}$ at room temperature. Indirect detection of BSG protein was performed by incubating the sections for $45 \mathrm{~min}$ with avidin-biotinylated peroxidase complex reacted with $0.2 \mathrm{mg} / \mathrm{ml}$ Metal-3,3'-diaminobenzidine (Sigma) in Tris- $\mathrm{HCl}$ buffer $\mathrm{pH} 7.6$ for $3 \mathrm{~min}$ and finally counterstained with hematoxylin.

\section{RNA isolation and semi-quantitative RT-PCR}

Total RNA was extracted from tissue using TRIzol (Invitrogen) according to the manufacturer's instructions. One microgram total RNA was used in $20 \mu \mathrm{l}$ volume RT reactions using the iScript kit for RT-PCR following the manufacturer's instructions (Bio-Rad). Synthesized cDNA was then used for real-time PCR analysis.

Semi-quantitative PCR analyses were performed in $50 \mu \mathrm{l}$ volumes containing Platinum Taq PCR master mix (Cat\# 11306-016; Invitrogen) and $200 \mathrm{nM}$ specific primers for MMP1, -2, -3, -7, and H3F3. Amplification was performed for 35 cycles under standard hot-start PCR cycle parameters. Products were separated on 5\% agarose gels to identify the $100 \mathrm{bp}$ fragment for each gene. Gene Snap software (Ver 7.01, SynGene, Cambridge, UK) was used for the analysis of products, and densitometry was performed using Image J software $(\mathrm{NIH}$, Bethesda, MD, USA). Fold induction was expressed relative to $\mathrm{H} 3 \mathrm{~F} 3$ endogenous control gene after normalization for background signal.

Real-time PCR analyses were performed in $10 \mu \mathrm{l}$ volumes containing $1 \times$ TaqMan Universal PCR Master Mix No AmpErase UNG (Cat \# 4324018, Applied Biosystems, Atlanta, GA, USA), diluted cDNA, and Rnase-free water. The primer probe set used for BSG amplification was designed by the $20 \times$ Assays-by-Design Gene Expression Assays from Applied Biosystems. Histone 3.3 primers and probe were designed for the use as an internal endogenous control (see Table 1 for sequence information). Minor groove binding probes were labeled with fluorescent reporter dye FAM to directly detect PCR products. Real-time PCR amplification and detection were performed in MicroAmp optical 384-well reaction plates using the $\mathrm{ABI}$ Prism 7000 sequence detection system. Amplification conditions included hold $10 \mathrm{~min}$ at $95^{\circ} \mathrm{C}, 40$ thermal cycles of denaturing for $15 \mathrm{~s}$ at $95^{\circ} \mathrm{C}$, and annealing/extension for $1 \mathrm{~min}$ at $60{ }^{\circ} \mathrm{C}$. Relative fold induction levels were calculated using the comparative $C_{\mathrm{t}}$ method for separate tube amplification.

\section{Statistical analysis}

An ANOVA model to evaluate experimental variability between the three individual experiments was used to determine differences in the disease progression. The difference between the threshold cycle of BSG and H3F3 $\left(\Delta C_{t}\right)$ was analyzed using post hoc orthogonal comparisons to determine

Table 1 Sequences of primer sets and probes used for TaqMan PCR.

\begin{tabular}{llll}
\hline Gene & Forward primer & Reverse primer & Probe \\
\hline H3F3 & GGCGCTCCGTGAAATTAGAC & CGCTGGAAGGGAAGTTTGC & TTATCAGAAGTCCACTGAACTTCTGATT \\
$B S G$ & CCGGCCAGAAAACGGACTT & AGGAAGACGCAGGAGTACTCT & TCGTCGGAGTCCACCTCG \\
\hline
\end{tabular}


statistical significance for each sample. Orthogonal contrasts statements were written that measured for differences in the stage of cycle for the control animals, in ovariectomized steroid treatment groups, and the stage of disease for the disease progression. Significance was measured against controls as well as against other timepoints of disease. Threshold cycle was defined as the cycle number where all transcripts are in the linear phase of amplification. The difference between BSG and H3F3 was then normalized to menstrual tissue for cycling and ovariectomized animals or control animal expression for diseased animals and expressed as a relative fold difference.

\section{Declaration of interest}

The authors declare that there is no conflict of interest that would prejudice the impartiality of this work.

\section{Funding}

Supported by Eunice Kennedy Shriver National Institute of Child Health and Human Development/National Institutes of Health through cooperative agreement U54 HD 40093 as part of the Specialized Cooperative Centers Program in Reproduction and Infertility Research.

\section{Acknowledgements}

The authors would like to thank Patricia Mavrogianis from the Imaging and Microscopy Core at the University of Illinois for the processing of tissues. We would also like to thank the late Dr Masaaki Nakai for his technical guidance with the immunohistochemical protocol and imaging analysis.

\section{References}

Aghajanova L, Velarde MC \& Giudice LC 2009 The progesterone receptor coactivator Hic-5 is involved in the pathophysiology of endometriosis. Endocrinology 150 3863-3870. (doi:10.1210/en.2009-0008)

Attar E, Tokunaga H, Imir G, Yilmaz MB, Redwine D, Putman M, Gurates B, Attar R, Yaegashi N, Hales DB et al. 2009 Prostaglandin $E_{2}$ via steroidogenic factor-1 coordinately regulates transcription of steroidogenic genes necessary for estrogen synthesis in endometriosis. Journal of Clinical Endocrinology and Metabolism 94 623-631. (doi:10. 1210/jc.2008-1180)

Braundmeier AG \& Nowak RA 2006 Cytokines regulate matrix metalloproteinases in human uterine endometrial fibroblast cells through a mechanism that does not involve increases in extracellular matrix metalloproteinase inducer. American Journal of Reproductive Immunology 56 201-214. (doi:10.1111/j.1600-0897.2006.00418.x)

Braundmeier AG, Fazleabas AT, Lessey BA, Guo H, Toole BP \& Nowak RA 2006 Extracellular matrix metalloproteinase inducer regulates metalloproteinases in human uterine endometrium. Journal of Clinical Endocrinology and Metabolism 91 2358-2365. (doi:10.1210/jc.20050601)

Brenner RM, Rudolph L, Matrisian L \& Slayden OD 1996 Non-human primate models; artificial menstrual cycles, endometrial matrix metalloproteinases and s.c. endometrial grafts. Human Reproduction 11 (Supplement 2) 150-164. (doi:10.1093/humrep/11.suppl_2.150)

Bruner KL, Eisenberg E, Gorstein F \& Osteen KG 1999 Progesterone and transforming growth factor-beta coordinately regulate suppression of endometrial matrix metalloproteinases in a model of experimental endometriosis. Steroids 64 648-653. (doi:10.1016/S0039-128X(99) 00048-3)
Bruner-Tran KL, Eisenberg E, Yeaman GR, Anderson TA, McBean J \& Osteen KG 2002 Steroid and cytokine regulation of matrix metalloproteinase expression in endometriosis and the establishment of experimental endometriosis in nude mice. Journal of Clinical Endocrinology and Metabolism 87 4782-4791. (doi:10.1210/jc.2002-020418)

Chen L, Nakai M, Belton RJ Jr \& Nowak RA 2007 Expression of extracellular matrix metalloproteinase inducer and matrix metalloproteinases during mouse embryonic development. Reproduction 133 405-414. (doi:10.1530/rep.1.01020)

Cox KE, Sharpe-Timms KL, Kamiya N, Saraf M, Donnelly KM \& Fazleabas AT 2000 Differential regulation of stromelysin-1 (matrix metalloproteinase-3) and matrilysin (matrix metalloproteinase-7) in baboon endometrium. Journal of the Society for Gynecologic Investigation 7 242-248. (doi:10.1016/S1071-5576(00)00062-9)

Curry TE Jr \& Osteen KG 2003 The matrix metalloproteinase system: changes, regulation, and impact throughout the ovarian and uterine reproductive cycle. Endocrine Reviews 24 428-465. (doi:10.1210/er. 2002-0005)

D'Hooghe TM 1997 Clinical relevance of the baboon as a model for the study of endometriosis. Fertility and Sterility 68 613-625. (doi:10.1016/ S0015-0282(97)00277-X)

D'Hooghe TM, Bambra CS, Raeymaekers BM, De Jonge I, Lauweryns JM \& Koninckx PR 1995 Intrapelvic injection of menstrual endometrium causes endometriosis in baboons (Papio cynocephalus and Papio anubis). American Journal of Obstetrics and Gynecology 173 125-134. (doi:10.1016/0002-9378(95)90180-9)

Fazleabas AT 2010 Progesterone resistance in a baboon model of endometriosis. Seminars in Reproductive Medicine 28 75-80. (doi:10. 1055/s-0029-1242997)

Fazleabas AT, Miller JB \& Verhage HG 1988 Synthesis and release of estrogen- and progesterone-dependent proteins by the baboon (Papio anubis) uterine endometrium. Biology of Reproduction 39 729-736. (doi:10.1095/biolreprod39.3.729)

Fazleabas AT, Bell SC, Fleming S, Sun J \& Lessey BA 1997a Distribution of integrins and the extracellular matrix proteins in the baboon endometrium during the menstrual cycle and early pregnancy. Biology of Reproduction 56 348-356. (doi:10.1095/biolreprod56.2.348)

Fazleabas AT, Donnelly KM, Hild-Petito S, Hausermann HM \& Verhage HG $1997 b$ Secretory proteins of the baboon (Papio anubis) endometrium: regulation during the menstrual cycle and early pregnancy. Human Reproduction Update 3 553-559. (doi:10.1093/ humupd/3.6.553)

Fazleabas AT, Donnelly KM, Srinivasan S, Fortman JD \& Miller JB 1999 Modulation of the baboon (Papio anubis) uterine endometrium by chorionic gonadotrophin during the period of uterine receptivity. PNAS 96 2543-2548. (doi:10.1073/pnas.96.5.2543)

Fazleabas AT, Brudney A, Gurates B, Chai D \& Bulun S 2002 A modified baboon model for endometriosis. Annals of the New York Academy of Sciences 955 308-317. (doi:10.1111/j.1749-6632.2002.tb02791.x)

Fazleabas AT, Brudney A, Chai D, Langoi D \& Bulun SE 2003 Steroid receptor and aromatase expression in baboon endometriotic lesions. Fertility and Sterility 80 (Supplement 2) 820-827. (doi:10.1016/S00150282(03)00982-8)

Folse D \& Stout L 1978 Endometriosis in the baboon. Laboratory Animal Science 28 217-219.

Gaetje R, Holtrich U, Engels K, Kourtis K, Cikrit E, Kissler S, Rody A, Karn T \& Kaufmann M 2007 Expression of membrane-type 5 matrix metalloproteinase in human endometrium and endometriosis. Gynecological Endocrinology 23 567-573. (doi:10.1080/09513590701556921)

Giudice LC 2004 Microarray expression profiling reveals candidate genes for human uterine receptivity. American Journal of Pharmacogenomics 4 299-312. (doi:10.2165/00129785-200404050-00003)

Hastings JM, Jackson KS, Mavrogianis PA \& Fazleabas AT 2006 The estrogen early response gene FOS is altered in a baboon model of endometriosis. Biology of Reproduction 75 176-182. (doi:10.1095/ biolreprod.106.052852)

Hausermann HM, Donnelly KM, Bell SC, Verhage HG \& Fazleabas AT 1998 Regulation of the glycosylated beta-lactoglobulin homolog, glycodelin [placental protein 14:(PP14)] in the baboon (Papio anubis) uterus. Journal of Clinical Endocrinology and Metabolism 83 1226-1233. (doi:10.1210/jc.83.4.1226) 
Hirota Y, Tranguch S, Daikoku T, Hasegawa A, Osuga Y, Taketani Y \& Dey SK 2008 Deficiency of immunophilin FKBP52 promotes endometriosis. American Journal of Pathology 173 1747-1757. (doi:10.2353/ ajpath.2008.080527)

Igakura T, Kadomatsu K, Kaname T, Muramatsu H, Fan QW, Miyauchi T, Toyama Y, Kuno N, Yuasa S, Takahashi M et al. 1998 A null mutation in basigin, an immunoglobulin superfamily member, indicates its important roles in peri-implantation development and spermatogenesis. Developmental Biology 194 152-165. (doi:10.1006/dbio.1997.8819)

Jackson KS, Brudney A, Hastings JM, Mavrogianis PA, Kim JJ \& Fazleabas AT 2007 The altered distribution of the steroid hormone receptors and the chaperone immunophilin FKBP52 in a baboon model of endometriosis is associated with progesterone resistance during the window of uterine receptivity. Reproductive Sciences 14 137-150. (doi:10.1177/1933719106298409)

Jones CJ, Nardo LG, Litta P \& Fazleabas AT 2009 Peritoneal ectopic lesions from women with endometriosis show abnormalities in progesteronedependent glycan expression. Fertility and Sterility 91 1608-1610. (doi:10.1016/j.fertnstert.2008.11.032)

Kim JJ, Taylor HS, Lu Z, Ladhani O, Hastings JM, Jackson KS, Wu Y, Guo SW \& Fazleabas AT 2007 Altered expression of HOXA10 in endometriosis: potential role in decidualization. Molecular Human Reproduction 13 323-332. (doi:10.1093/molehr/gam005)

Kokorine I, Nisolle M, Donnez J, Eeckhout Y, Courtoy PJ \& Marbaix E 1997 Expression of interstitial collagenase (matrix metalloproteinase-1) is related to the activity of human endometriotic lesions. Fertility and Sterility 68 246-251. (doi:10.1016/S0015-0282(97)81510-5)

Merrill J 1968 Spontaneous endometriosis in the Kenya baboon. American Journal of Obstetrics and Gynecology 101 569-570.

Monckedieck V, Sannecke C, Husen B, Kumbartski M, Kimmig R, Totsch M, Winterhager E \& Grummer R 2009 Progestins inhibit expression of MMPs and of angiogenic factors in human ectopic endometrial lesions in a mouse model. Molecular Human Reproduction 15 633-643. (doi:10. 1093/molehr/gap063)

Muramatsu T \& Miyauchi T 2003 Basigin (CD147): a multifunctional transmembrane protein involved in reproduction, neural function, inflammation and tumor invasion. Histology and Histopathology 18 981-987.

Noguchi Y, Sato T, Hirata M, Hara T, Ohama K \& Ito A 2003 Identification and characterization of extracellular matrix metalloproteinase inducer in human endometrium during the menstrual cycle in vivo and in vitro. Journal of Clinical Endocrinology and Metabolism 88 6063-6072. (doi:10.1210/jc.2003-030457)
Osteen KG, Bruner-Tran KL, Ong D \& Eisenberg E 2002 Paracrine mediators of endometrial matrix metalloproteinase expression: potential targets for progestin-based treatment of endometriosis. Annals of the New York Academy of Sciences 955 139-146. (doi:10.1111/j.17496632.2002.tb02774.x)

Rodgers WH, Matrisian LM, Giudice LC, Dsupin B, Cannon P, Svitek C, Gorstein F \& Osteen KG 1994 Patterns of matrix metalloproteinase expression in cycling endometrium imply differential functions and regulation by steroid hormones. Journal of Clinical Investigation 94 946-953. (doi:10.1172/JCl117461)

Salamonsen LA \& Woolley DE 1999 Menstruation: induction by matrix metalloproteinases and inflammatory cells. Journal of Reproductive Immunology 44 1-27. (doi:10.1016/S0165-0378(99)00002-9)

Salamonsen LA, Butt AR, Hammond FR, Garcia S \& Zhang J 1997 Production of endometrial matrix metalloproteinases, but not their tissue inhibitors, is modulated by progesterone withdrawal in an in vitro model for menstruation. Journal of Clinical Endocrinology and Metabolism 82 1409-1415. (doi:10.1210/jc.82.5.1409)

Sampson J 1940 The development of the implantation theory for the origin of peritoneal endometriosis. American Journal of Obstetrics and Gynecology 40 549-557.

Sun J \& Hemler ME 2001 Regulation of MMP-1 and MMP-2 production through CD147/extracellular matrix metalloproteinase inducer interactions. Cancer Research $612276-2281$.

Talbi S, Hastings JM, Hamilton A, Germeyer A, Jackson K, Giudice L \& Fazleabas A 2006 Global endometrial gene expression analysis in a baboon model of endometriosis. Biology of Reproduction (Special Issue) p. 102. Abstract 138.

Tranguch S, Wang H, Daikoku T, Xie H, Smith DF \& Dey SK 2007 FKBP52 deficiency-conferred uterine progesterone resistance is genetic background and pregnancy stage specific. Journal of Clinical Investigation 117 1824-1834. (doi:10.1172/JCl31622)

Xiao LJ, Chang H, Ding NZ, Ni H, Kadomatsu K \& Yang ZM 2002 Basigin expression and hormonal regulation in mouse uterus during the periimplantation period. Molecular Reproduction and Development 63 47-54. (doi:10.1002/mrd.10128)

Received 26 October 2009

First decision 5 January 2010

Revised manuscript received 3 September 2010

Accepted 13 September 2010 